\title{
Los ayllus de la porción oriental del departamento del Cusco. Aproximación comparativa desde el Collasuyu
}

Les ayllus de la région orientale du département du Cusco. Une approche comparative à partir du Collasuyu

The ayllus of Eastern Cusco: Comparative approach from Collasuyu

Pablo F. Sendón

\section{OpenEdition}

Journals

Edición electrónica

URL: http://journals.openedition.org/bifea/2867

DOI: $10.4000 /$ bifea.2867

ISSN: 2076-5827

Editor

Institut Français d'Études Andines

Edición impresa

Fecha de publicación: 1 abril 2009

Paginación: 107-130

ISSN: 0303-7495

\section{Referencia electrónica}

Pablo F. Sendón, « Los ayllus de la porción oriental del departamento del Cusco. Aproximación

comparativa desde el Collasuyu », Bulletin de l'Institut français d'études andines [En línea], 38 (1) | 2009,

Publicado el 01 octubre 2009, consultado el 17 noviembre 2020. URL : http://journals.openedition.org/ bifea/2867 ; DOI : https://doi.org/10.4000/bifea.2867

\section{(c) (i) $\Theta$}

Les contenus du Bulletin de l'Institut français d'études andines sont mis à disposition selon les termes de la licence Creative Commons Attribution - Pas d'Utilisation Commerciale - Pas de Modification 4.0 International. 
Bulletin de l'Institut Français d'Études Andines / 2009, 38 ( 1): 107-130

\title{
Los ayllus de la porción oriental del departamento del Cusco. Aproximación comparativa desde el Collasuyu*
}

\author{
Pablo F. Sendón ${ }^{* *}$
}

\begin{abstract}
Resumen
El presente artículo discute la relevancia y el funcionamiento del ayllu entre las poblaciones campesino indígenas quechuahablantes de la porción oriental del departamento del Cusco a partir de dos ejemplos etnográficos: Phinaya (distrito de Pitumarca, provincia de Canchis) y Marcapata (provincia de Quispicanchi). El análisis de la información de base sugiere que, a diferencia de lo que suponen los límites sociopolíticos impuestos por la sociedad mayor, características significativas de las poblaciones estudiadas —en sus aspectos morfológicos, rituales y simbólicos - comparten semejanzas notables con aquellas pertenecientes al Collasuyu. Se propone, así, relacionar la información etnográfica de la casuística surperuana con estudios etnográficos y etnohistóricos sobre poblaciones homólogas en Bolivia.
\end{abstract}

Palabras clave: ayllu, parentesco, ritual, ch’ullpas, sur peruano, Collasuyu

* El artículo es el resultado de una ponencia presentada por el autor en el seminario permanente del Centre for Amerindian Studies de la Universidad de St. Andrews (Escocia) en diciembre de 2006, en el marco del programa British Academy Visiting Fellowsip 2006-2007 (VF2006/42688). Agradecemos a The British Academy y a Tristan Platt, nuestro anfitrión en St. Andrews, por el apoyo brindado durante la estadía. Una versión preliminar fue discutida en el Centro Bartolomé de las Casas (Cusco) y en el Instituto de Estudios Peruanos (Lima) en agosto de 2007. Agradecemos a Xavier Ricard, Javier Monroe, Ramón Pajuelo, Carlos Iván Degregori, Tom Zuidema, Jürgen Golte y Juan Ossio por sus comentarios.

** Investigador del Consejo Nacional de Investigaciones Científicas y Técnicas (CONICET), Argentina. Sección Etnohistoria, ICA-FFyL, UBA, Puan 480 (1406), Buenos Aires. E-mail: psendon@yahoo.com 


\title{
Les ayllus de la région orientale du département du Cusco. Une approche comparative à partir du Collasuyu
}

\author{
Résumé
}

Cet article évalue l'importance et le fonctionnement de l'ayllu chez les populations paysannesindiennes de langue quechua de la région orientale du département du Cusco, à partir de deux exemples ethnographiques: Phinaya (district de Pitumarca, province de Canchis) et Marcapata (province de Quispicanchi). L'analyse de l'information de base suggère que, à la différence de ce que supposent les limites socio-politiques imposées para la société globale, des caractéristiques significatives de ces populations (aspects morphologiques, rituels et symboliques) montrent des ressemblances notables avec celles du Collasuyu. L'article propose donc de comparer l'information ethnographique de la casuistique sud-péruvienne avec des études ethnographiques et ethnohistoriques de populations analogues en Bolivie.

Mots clés : ayllu, parenté, rituel, ch'ullpas, sud péruvien, Collasuyu

\section{The ayllus of Eastern Cusco: Comparative approach from Collasuyu}

\begin{abstract}
The article discusses the relevance and performance of the ayllu among the Quechua-speaking, indigenous-peasant populations of the Eastern corner of the Department of Cusco, focusing on two concrete ethnographic examples: Phinaya (District of Pitumarca, Province of Canchis), and Marcapata (Province of Quispicanchi). Considering several morphological, ritual and symbolic aspects, the analysis of field data suggests that despite social and political boundaries significant characteristics of the Eastern Cusco populations share outstanding similarities with the peoples of Collasuyu. Therefore, the paper proposes the necessity of linking the ethnographic data about Southern Peruvian populations with the ethnographical and ethnohistorical research concerning their Bolivian homologues.
\end{abstract}

Key words: ayllu, kinship, ritual, ch 'ullpas, Southern Peru, Collasuyu

\section{INTRODUCCIÓN}

El estudio etnográfico y etnológico de las poblaciones «campesino-indígenas» (Ricard Lanata, 2005) que habitan los Andes peruanos impone tres distinciones analíticas. La primera remite a los términos «comunidad» y «ayllu». Mientras que el primero posee un sentido preciso en la historia del Perú republicano en relación con el problema del reconocimiento institucional y la ulterior inclusión de la población indígena en el territorio nacional; el segundo remite a un principio de organización social propio de la tradición andina (Alber, 1999; Mossbrucker, 1990; Golte, 1992). En tanto principio de organización social, el ayllu está fundamentalmente relacionado con la dimensión parental de la vida social de los miembros que lo constituyen (Arnold, 1998; Ossio Acuña, 1981; Sendón, en prensa). Es decir, el ayllu es una agrupación de individuos unidos entre sí a través de vínculos de parentesco. Son estas mismas relaciones de parentesco las que definen no solo la pertenencia al ayllu — condición no definitoria 
de la pertenencia institucional a la comunidad — sino también sus contornos y sus límites en tanto forma de organización social. Ello involucra una segunda distinción, relativa esta vez a los términos «principio» y «forma». Las formas a través de las cuales se manifiesta el ayllu - duales, tripartitas, cuatripartitas, etc.- no invalidan que sus principios o fundamentos remitan siempre al universo de las relaciones de parentesco. Estas últimas, sin embargo, están también sujetas a variaciones ya que las agrupaciones de parientes, sus ordenamientos en unidades mayores, y las dinámicas sociales en el interior de cada una de estas esferas - y entre sí- no son siempre las mismas. La tercera distinción que se debe tener en cuenta es que los estudios sobre ayllu, parentesco y organización social en los Andes se agrupan en torno a dos grandes líneas de análisis, aquella perteneciente a la investigación etnohistórica sobre las sociedades Inca y Aymará — mayoritariamente concentrada en la exégesis de fuentes coloniales que contienen información relativa a las terminologías de parentesco- - y la investigación etnográfica que, desde el terreno, se preocupó también por el análisis de las prácticas sociales. Aunque el ayllu en su versión temprana no tiene por qué coincidir con las versiones contemporáneas que se tienen acerca de él (Skar, 1997 [1982]), ello no involucra que algunos aspectos identificados sobre la primera no puedan ser fuente de reflexión acerca de las segundas.

En este trabajo se discute la casuística etnográfica de dos poblaciones campesinoindígenas, quechuahablantes contemporáneas, ubicadas en el extremo oriental del departamento de Cusco (provincias de Canchis y Quispicanchi) desde la perspectiva que ofrece la triple distinción propuesta. En primer lugar, si bien organizadas en «comunidades campesinas», ambas poblaciones también lo están en ayllus, lo que plantea la necesidad de establecer las diferencias entre ambos niveles de organización. En segundo lugar, aunque en su fisonomía ambos ayllus difieren entre sí, manifestándose de manera dual en un caso y cuatripartita en el otro, los principios que los fundamentan son los mismos: las relaciones de parentesco que unen a sus miembros constitutivos. La identificación de estos principios y los mecanismos mediante los cuales son ejecutados permiten una caracterización precisa del funcionamiento, contornos y límites del ayllu en esta porción de los Andes. Sin embargo, el ayllu no se reduce exclusivamente a ello, sino que también involucra el ámbito de las prácticas sociales —económicas, políticas y rituales- y las conceptualizaciones nativas acerca de ellas —que son expresadas en el idioma del parentesco- . En tercer lugar, algunas de las características definitorias del funcionamiento del ayllu en ambos casos remiten directamente a sus pares pretéritos, invitando de este modo a ampliar la escala temporal de la comparación. Finalmente, debido a sus respectivas morfologías, los fundamentos parentales sobre las que descansan, las prácticas sociales y rituales a ellas asociadas —así como también a su ubicación geográfica y ecológica y las actividades económicas en las que se encuentran comprometidas- presentan semejanzas significativas con poblaciones pertenecientes al altiplano boliviano y al universo cultural aymará. Se propone, de esta manera, extender la escala espacial de la comparación hacia una zona con la que, por lo general, la casuística cusqueña no ha sido confrontada, y solo en relación con algunos elementos precisos que, hilvanados desde el Collasuyu, posibilitarían una mejor comprensión de los casos analizados.

\section{LOS AYLLUS DE PHINAYA}

La comunidad campesina de Phinaya se ubica en las alturas del extremo nororiental del distrito de Pitumarca (Canchis) por sobre los 4500 msnm. Su población, exclusivamente dedicada a la actividad pastoril, asciende a unas 130 familias nucleares (o 650 individuos) 
que ocupan un territorio de aproximadamente 40000 hectáreas. «Phinaya» no es solo el nombre de la «comunidad» sino también de uno de los ocho sectores en los que está dividida y del «centro poblado menor» del que forma parte con otras cuatro comunidades de la región. En calidad de unidad social que conforma (y preside) el centro poblado, los individuos que la constituyen detentan los estatus de «propietarios», «Comuneros» y «pastores» de acuerdo con el tipo de acceso que tienen al territorio: mientras que los primeros son dueños de las porciones en las que crían sus ganados, el usufructo al que tienen acceso los segundos está reservado a aquellas porciones que fueron afectadas por la reforma agraria de 1969. El estatus de pastor es residual, tratándose de individuos cuyo acceso al territorio está mediatizado por los vínculos que mantienen con las familias propietarias o comuneras. Cuatro de los sectores son privados y cuatro comunales, reservándose el término «comunidad» a estos últimos, a las familias que los usufructúan y a sus respectivos órganos de gobierno. Si bien la fisonomía actual de Phinaya es resultado de un entreverado proceso histórico de metamorfosis jurídico-institucional acerca del cual no es posible detenerse aquí (Sendón, 2001), lo cierto es que en términos institucionales la división entre propietarios y comuneros involucra varios planos de fragmentación social (Molinié-Fioravanti, 1986 [1978]). Resulta ilustrativo señalar la afiliación y participación selectiva de las familias en los diferentes órganos de gobierno que regulan los también diferentes niveles de organización política del grupo. Ellos son tres. El centro poblado menor tiene jurisdicción sobre las cinco comunidades que lo componen, sus autoridades se eligen cada cuatro años y en la toma de decisiones de su asamblea participan exclusivamente los individuos empadronados sean ellos propietarios, comuneros o pastores. En el nivel de la comunidad, con jurisdicción sobre los territorios comunales, las elecciones de las autoridades se celebran cada dos años y en ellas participan exclusivamente los comuneros debidamente empadronados ante asamblea. Lo mismo ocurre en el nivel menos inclusivo del sector, en el que participan exclusivamente las familias que lo habitan. Ahora bien, Phinaya es, y ha sido, una unidad social con contornos precisos y es percibida como tal por los propios phinayenses. ¿Cuáles son los fundamentos de la cohesión del grupo en la actualidad y a lo largo del tiempo? Fundamentalmente dos: su organización en ayllu y las relaciones de parentesco entre los miembros de las diversas familias nucleares.

Phinaya está organizada en dos mitades denominadas Consachapi e llave o, también, hatun ayllu (ayllu grande) y huch 'uy ayllu (ayllu pequeño). Desde esta perspectiva, las instancias de fragmentación mencionadas parecieran quedar suspendidas en virtud del funcionamiento de una serie de instituciones mediante las cuales el ayllu se expresa involucrando a todo el universo social. El territorio está dividido en dos porciones, pertenecientes a cada ayllu, y las mismas familias se dividen de acuerdo a su afiliación a cada una de ellas. Aunque el ayllu grande cuenta con mayor cantidad de tierras y familias que el ayllu pequeño, ambos están conformados por cuatro de los sectores — dos comunales y dos privadosen los que se divide la población. Junto con este «dualismo territorial» existe también una «división dual del trabajo», que se expresa en todas las actividades que involucran la participación de los ayllus dejando impreso su sello en sus respectivos productos. Una tercera manifestación institucional del ayllu está relacionada con el funcionamiento de la organización política y sus autoridades respectivas. La autoridad más inclusiva de los phinayenses es el Teniente Gobernador, con jurisdicción sobre los dos ayllus. Ella es secundada por cuatro Tenientes Auxiliares, dos por cada ayllu, con jurisdicción sobre sus respectivos ayllus de pertenencia. En la elección de estos cargos están involucradas todas las familias de Phinaya y los mecanismos para efectivizarla están pautados por una suerte de «dualismo político». Mientras que el Teniente Gobernador es elegido entre dos candidatos, pertenecientes a cada ayllu, sus auxiliares son elegidos entre ocho, cuatro de Consachapi 
y cuatro de llave. Estos dos últimos nombres remiten, a su vez, al de dos de los siete ayllus que componían el entonces repartimiento de Pitumarca (desde fines del siglo XVIII hasta fines del siglo XIX), así como al de dos de las cuatro comunidades que, en su conjunto, conforman el pueblo de Pitumarca — capital del distrito- . En calidad de pueblo dividido en dos mitades Phinaya es, no sin ciertos problemas, «anexo» de una de las comunidades de la capital distrital, y la tenencia de gobernación depende de ella1. Ahora bien, ¿alcanzan estas diferentes manifestaciones dualistas para dar cuenta cabal del funcionamiento y constitución de los ayllus phinayenses? Es decir, ¿explica el «dualismo institucional» —la expresión del ayllu — aquello que es expresado — el ayllu —? De ser válida esta distinción, ¿cuáles son los fundamentos sociológicos sobre los que descansa el ayllu en Phinaya?

Las familias nucleares de Phinaya se reordenan en un número variable de líneas de descendencia agnaticias que ocupan porciones precisas del territorio a lo largo de las generaciones, estableciéndose así una asociación entre patronímicos y la toponimia vernácula. Entre las líneas se establecen, también de generación en generación, estrechos vínculos de alianza en virtud de los cuales se conforma una tupida red de parentesco que se extiende sobre un plano vertical y otro horizontal. Es decir, cada una de las mitades del territorio está, a su vez, subdividida en porciones territoriales menores ocupadas por familias nucleares relacionadas a través de los vínculos agnaticios existentes entre sus respectivos jefes (varones). La reproducción $-\mathrm{O}$ el éxito en la continuidad de la explotación de porciones del territorio- de estas líneas involucra el intercambio más o menos sistemático de sus respectivas mujeres quienes — consecuentemente con la práctica de residencia postmatrimonial dominante - se trasladan a residir a los territorios ocupados por sus maridos y respectivos agnados. El intercambio de mujeres involucra diversos grados de endogamia y exogamia. Si bien la mayoría de las uniones conyugales se celebran entre partenaires pertenecientes a una misma mitad, no son estadísticamente menos significativos los casos en que los partenaires de una unión pertenecen a las mitades opuestas, así como tampoco aquellos en los que son los hombres quienes se trasladan a residir a los terrenos de sus esposas. En este último caso puede tratarse tanto de phinayenses como de individuos foráneos. La presencia más o menos continua a lo largo de las generaciones de la uxorilocalidad está relacionada con otra de las características de las líneas de descendencia: ellas, lejos de continuar indefinidamente, están sujetas a un proceso de continuidad y ruptura a través del cual aquellas líneas que desaparecen (debido a que en alguna generación la descendencia de un antepasado masculino común consta exclusivamente de mujeres, a que la descendencia masculina en esa generación migra, o a ambas circunstancias) son suplantadas o reinauguradas por otras mediante la introducción de un nuevo patronímico producto de la unión matrimonial —y ulterior residencia uxorilocal— de un hombre con una mujer de la línea interrumpida. Debido a cierta fragilidad lineal (mas no así colateral) en la memoria genealógica, así como también al ejercicio clasificatorio al que son sometidos los miembros del ayllu mediante la terminología de parentesco en uso, la situación en cierto modo atípica de una línea inaugurada a partir del traslado de un hombre (phinayense o foráneo) al terreno que ocupa la familia (de orientación) de su mujer se irá relajando, e incluso olvidando, a medida que la familia (de procreación) de este mismo hombre sea exitosa en la explotación continua de la porción del territorio que le toca ocupar.

1 La primera ocasión en la que aparece consignado el término Phinaya en una fuente oficial es en el libro de contribución tributaria del año 1883 como «caserío de Phinaya de llave», ubicado en la «parcialidad llave» que, junto con otras tres, conformaban el «pueblo de Pitumarca» perteneciente al «distrito de Checacupe». Las parcialidades (siete en total) constituyen las unidades político administrativas en las que estaban divididos los repartimientos de Pitumarca y Checacupe durante la mayor parte del siglo XIX e incluso fines del XVIII (Sendón, 2001). 
Son estas variables —agnación, virilocalidad, endogamia en el nivel de la mitad, exogamia entre mitades, migración y fragilidad en la memoria genealógica - las que delinean los contornos del ayllu phinayense, permitiendo no solo su constitución sino también su renovación a lo largo de las generaciones mediante la incorporación de elementos foráneos. Si bien existe una correspondencia estadística elocuente entre estas variables y la forma de organización social descubierta, lo cierto es que ello es una cara de la moneda. La otra está relacionada con la movilidad espacial de las sociedades pastoriles de esta porción del sur peruano, así como con las propias conceptualizaciones nativas de las prácticas vernáculas - expresadas en el idioma del parentesco 2 -

Existen cuatro posibilidades con respecto al lugar de origen de los jefes de familia de Phinaya (Sendón, 2005): a) ambos, hombre y mujer, son originarios; b) el hombre es originario y la mujer foránea (o su lugar de origen desconocido); c) el hombre es foráneo (o su lugar de origen desconocido) y la mujer phinayense y d) ambos son foráneos (o sus lugares de orígenes desconocidos). El análisis estadístico demostró que existe una mayor concentración de casos de tipo «a» y «d» por sobre los dos restantes, y una mayor concentración de casos «b» sobre «c». Si bien estas tasas se corroboran a lo largo de las generaciones, el número de casos «d» aumenta significativamente a medida que se asciende en ellas. Esto se relaciona con las características del ayllu phinayense: endogamia en el nivel del pueblo debido a la concentración de casos «a»; fuerte tendencia a la virilocalidad por la mayor concentración de casos «b» sobre «c»; fragilidad en la memoria genealógica debido a la amnesia relativa al lugar de origen de muchos de los ascendientes y, finalmente, una importante tendencia migratoria por el protagonismo de casos «d» —lo que evidencia, a su vez, un tipo de movilidad espacial propio de las sociedades pastoriles de los Andes centrales y meridionales-.

Los centros de migración hacia Phinaya se ubican en un espacio relativamente reducido —alrededor de la intersección del meridiano 71 y el paralelo 14- que no obstante presenta diferencias importantes en sus respectivas especializaciones productivas (fig. 1). La mayoría de la población migrante proviene —en términos de su magnitud numérica- del distrito de Marcapata (departamento de Cusco), dedicado a la actividad agrícola y pastoril; las poblaciones altoandinas de las provincias de Carabaya y Melgar del departamento de Puno, dedicadas exclusivamente a la actividad pastoril; y las poblaciones que, junto con Phinaya, ocupan una región excepcional en la provincia y están, también, comprometidas en la crianza de ganado. Phinaya no cuenta con pitumarquinos entre sus miembros.

Desde el Cusco, en dirección sudeste, Canchis está cruzada por el río Vilcanota y las capitales distritales se ubican a una u otra de sus márgenes a una altura promedio de $3400 \mathrm{msnm}$. Las poblaciones agrupadas alrededor de este eje se dedican fundamentalmente a la actividad agrícola. Desde este mismo eje, en dirección noroeste, los niveles altitudinales ascienden de manera abrupta en pocos kilómetros. Phinaya se encuentra a aproximadamente sesenta kilómetros de Pitumarca, a una altura que sobrepasa los 4500 msnm, en el extremo nororiental de la provincia — cercado por las cordilleras de Vilcanota y Carabaya- en el que ningún tipo de actividad agrícola es posible. Al tratarse de una sociedad agrícola, la población pitumarquina es fundamentalmente sedentaria mientras que Phinaya, sociedad de pastores, ha sido una población nómada por, al menos, dos motivos: la necesidad de trasladar el ganado de acuerdo con el ritmo impuesto por una biestacionalidad extrema y la

2 La escala temporal de la encuesta genealógica realizada en Phinaya (objeto de tratamiento pormenorizado en Sendón, 2005) es de aproximadamente cien años. Ella no solo corrobora la existencia de los ayllus en relación con la información de las fuentes oficiales sino también demuestra la recurrencia de las variables involucradas en su formación y reproducción a lo largo del tiempo. 


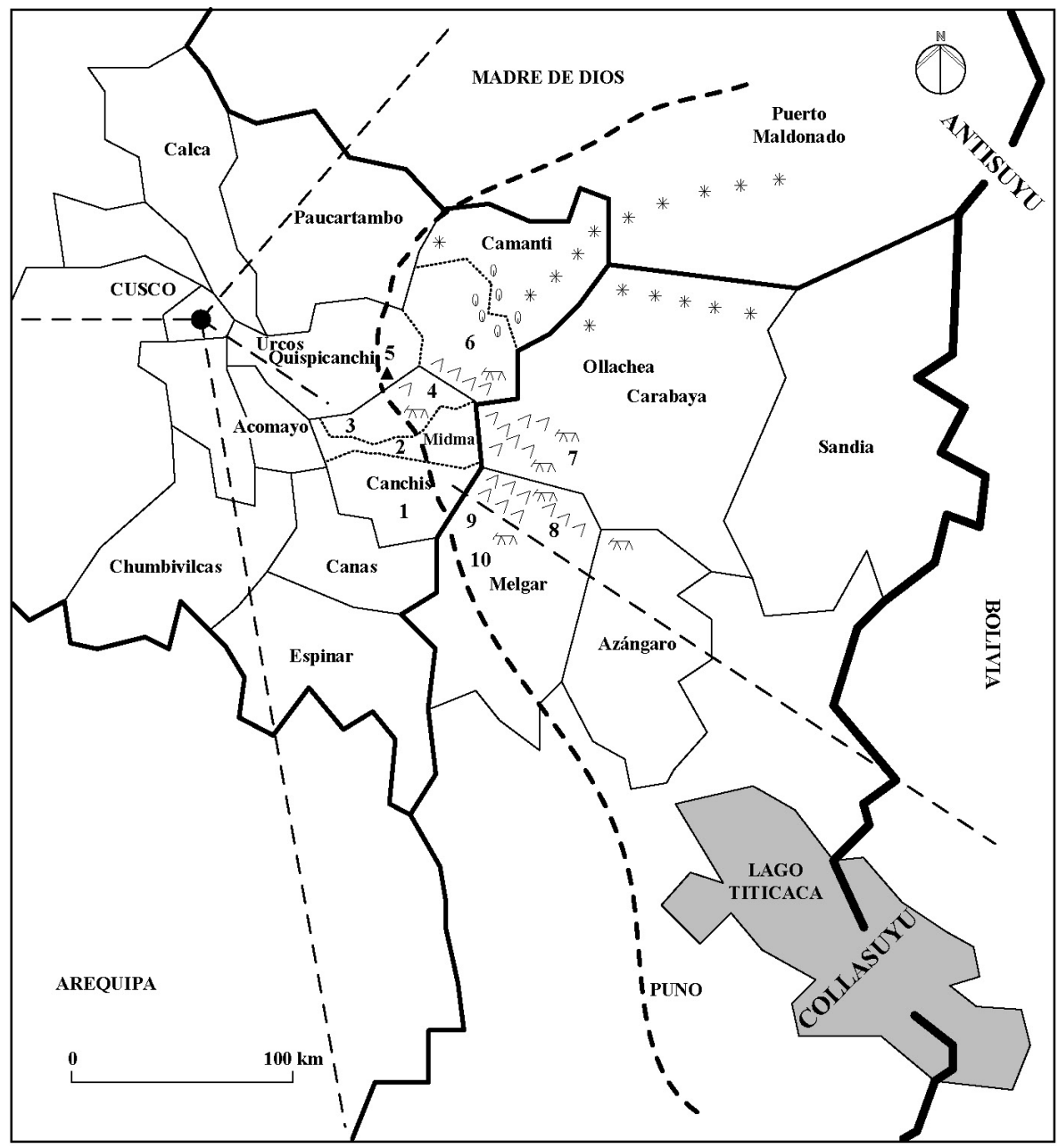

\section{Figura 1 - Croquis del sur de Cusco y regiones fronterizas}

Departamentos, provincias y distritos (confeccionado por el autor a partir de la cartografía elaborada en Deler et al., 1997)

Nivel altitudinal de los principales sitios de referencia: 1. Sicuani (3 $400 \mathrm{msnm}$ ) 2. Checacupe (3 $400 \mathrm{msnm})$

Pitumarca (3 $400 \mathrm{msnm})$ 4. Phinaya (+ $4000 \mathrm{msnm})$ 5. Nevado Ausangate (+ $6000 \mathrm{msnm})$ 6. Marcapata $(+/-3400 \mathrm{msnm})$ 7. Cordillera de Carabaya (+ $5000 \mathrm{msnm})$ 8. Cordillera Vilcanota (+ $5000 \mathrm{msnm})$ 9. Ñuñoa (+ $4000 \mathrm{msnm}) 10$. Santa Rosa (+ 4000 msnm) 
necesidad de trasladarse ella misma para abastecerse de productos ausentes en la zona que habita. Desde al menos fines del siglo XIX y hasta tiempo después de la reforma agraria, el segundo tipo de movilidad parece haber imperado en la región. Ello no solo lo prueban las genealogías sino también los recuerdos de sus protagonistas. Muchos de los antepasados de los phinayenses, provenientes de las zonas pastoriles de las provincias puneñas de Melgar y Carabaya, solían trasladarse con sus ganados hacia los valles marcapateños, e incluso más allá, en busca de productos agrícolas y tropicales para después regresar a sus lugares de origen. Estos traslados se realizaban al ritmo impuesto por condicionamientos ecológicos y sociales. En efecto, desde fines del siglo XIX, sino antes, las zonas altas de Canchis sufrieron el impacto de la expansión del sistema de hacienda, lo que redundó en una recomposición del territorio. Los antepasados de los phinayenses, organizados también entonces en dos ayllus, se vieron sometidos a una situación de expropiación y comenzaron a pastar sus propios ganados en las tierras de los hacendados. Por su parte, los pastores de Puno continuaban desplazándose lentamente hacia Marcapata y, en su trashumancia, solían residir durante algún tiempo en los territorios de las haciendas que cruzaban, una tras otra, ocupándose del pastoreo del ganado de los hacendados a cambio del acceso a pastos. Este tipo de movilidad, articulada a partir de las necesidades de un modo de vida pastoril, parece delinear un corredor espacial en el que Phinaya se presenta como un punto de paso — fluido — en un eje norte-sur que relaciona a las poblaciones pastoriles del Collasuyu con aquellas agrícolas y pastoriles del Antisuyu, así como también un punto de encuentro — conflictivo- en un eje este-oeste entre estas mismas poblaciones y aquellas fundamentalmente agrícolas en su búsqueda de expansión territorial. Desde esta perspectiva, Pitumarca parece terminar allí donde comienza Phinaya. La reforma agraria de 1969 — cuyos efectos se sintieron tardíamente en la zona-, al adscribir territorios específicos a las diversas poblaciones que se fueron organizando en «comunidades campesinas», cercenó los alcances de la escala espacial de movilidad reduciéndola a porciones territoriales circunscritas33.

Estas pautas de movilidad también se adecúan a las conceptualizaciones nativas sobre el ayllu. Para los phinayenses el ayllu involucra hablar de familia, es decir, el ayllu constituye un grupo de individuos emparentados entre sí que viven juntos. Ellos, al pertenecer al ayllu, pertenecen a la familia, ellos son familia y ayllu. Todos residen en el hatun ayllu y en el huch 'uy ayllu. A veces estos individuos acostumbran salir de su ayllu en busca de cónyuge. Por lo general, lo que ocurre es que el cónyuge deseado pertenece al mismo ayllu y las uniones matrimoniales se celebran en su interior. También existen casos en los que los cónyuges no son del mismo ayllu e incluso hay situaciones en las que uno de los cónyuges no es phinayense. En cualquiera de estas situaciones, el desplazamiento involucrado en cada nueva unión matrimonial trae aparejado una reclasificación de los partenaires que define sus nuevos estatus a los ojos de sus respectivos parientes y del pueblo en su totalidad. Esta reclasificación la provee la misma terminología de parentesco: toda nueva unión hace de uno los individuos un qatay y del otro un qhachun para sus respectivos parientes4.

En su sentido clasificatorio más elemental qatay y qhachun significan, respectivamente, «esposo de la hija-esposo de la hermana» y «esposa del hijo-esposa del hermano». Aunque su extensión clasificatoria no se restringe a estos cuatro grados de parentesco (Sendón, 2006), ellos sirven para dar cuenta aquí de una característica fundamental del ayllu en Phinaya. Los términos hacen referencia a un tipo de parientes específicos, los afines

3 Inamura (1981) reservó la etiqueta «trashumancia de fundo» para este tipo de movilidad.

4 El párrafo anterior parafrasea el relato — recogido in situ en septiembre de 2003 - ofrecido por el señor Octavio Ccanquere Tapia acerca de la naturaleza del ayllu phinayense. Para una versión completa, en castellano y quechua, ver Sendón (2006). 
masculinos y femeninos (de la propia generación y de la primera generación descendente) con quienes los parientes consanguíneos femeninos y masculinos de un grupo se han ligado en matrimonio. Los qatay y qhachun forman parte de un universo social con límites definidos — el ayllu — virtualmente conformado por consanguíneos y afines. Si se considera que en la inmensa mayoría de los matrimonios, los partenaires no están emparentados entre sí, los qatay y qhachun constituyen nudos fundamentales en el tejido de una red de parentesco que no solo se reproduce a lo largo del tiempo sino que lo hace en diversos grados, a través de la unión de líneas de descendencia de una misma mitad, de mitades distintas e incluso mediante la incorporación de elementos foráneos. Es decir, más que un criterio de diferenciación, la lógica que inspira el ejercicio clasificatorio de los términos anuncia un principio de generación: ellos constituyen la verdadera trama a través de la cual se tensan los hilos de una urdimbre que compele a hacer un pariente de un no-pariente. Estos «nuevos parientes», a su vez, ejercitan sobre terceros la misma lógica a la que ellos mismos son sometidos por los parientes de sus respectivos cónyuges.

\section{LOS AYLLUS DE MARCAPATA}

Desde el Ausangate, al norte de Phinaya y en dirección a la ceja de selva (departamento de Madre de Dios) se extiende, a manera de un tobogán que desciende desde los 2000 hasta los 1500 msnm, el distrito de Marcapata. Su territorio, que casi alcanza los $5000 \mathrm{~km}^{2}$ en el extremo nororiental de la provincia de Quispicanchi limita, al norte, con el distrito de Camanti y, al este, con el departamento de Puno. Su población, de aproximadamente 5000 individuos, está organizada en ocho comunidades, cuatro de ellas de creación reciente. En efecto, de acuerdo con los libros de matrículas de contribuyentes conservados en el Archivo Regional del Cusco, el repartimiento de Marcapata estaba conformado por los cuatro ayllus Collana Marcapata, Sahuancay, Puiqa y Collasuyu desde por lo menos el último cuarto del siglo XVIII. Es recién a mediados de la década de 1980, cuando son reconocidas las comunidades de Yanacocha-Inca Cancha, Unión Araza, Huaracone y Socapata5. El pueblo de Marcapata propiamente dicho (Ilaqta uhu) se presenta como el centro no solo político sino también ecológico del territorio distrital ya que, ubicado a los $3100 \mathrm{msnm}$, descansa sobre un eje horizontal (este-oeste) que divide los territorios dedicados al pastoreo y cultivos de altura de aquellos dedicados a los de tierras bajas. Desde esta perspectiva, el territorio se divide en una mitad meridional — cercana a las cordilleras de Carabaya y Vilcanota - y otra septentrional —adyacente al piedemonte amazónico - en la primera de las cuales están concentrados en su mayoría los terrenos de los cuatro ayllus, y en la segunda dos de las comunidades de reconocimiento reciente. Si bien la mayoría de ellas combinan la actividad agrícola y pastoril, existen tres casos de especialización.

La orientación espacial, circunscrita a la mitad meridional, y la relación jerárquica que mantienen los cuatro ayllus entre sí es la siguiente:

1. Collana Marcapata (oeste)

3. Puiqa (oeste)

2. Sahuancay (este)

4. Collasuyu (este)

5 En un estudio preliminar dedicado a Marcapata, a fines de la década de 1970, Yamamoto (1981) y Sato (1981) consignaron la existencia de solo las cuatro primeras — denominadas por ellos— «comunidades» o «sectores administrativos». 
Entre estos ayllus y las comunidades de creación reciente existe un vínculo genealógico, ya que las segundas son concebidas como «hijas» de los primeros. Dicho vínculo así como su distribución espacial (en la mitad meridional y septentrional) es el siguiente:

$\begin{array}{lll}\text { Yanacocha-Inca Cancha (sureste) } & \rightarrow & \text { Collana Marcapata } \\ \text { Socapata (noreste) } & \rightarrow & \text { Sahuancay } \\ \text { Unión Arasa (noroeste) } & \rightarrow & \text { Puiqa } \\ \text { Huaracone (sureste) } & \rightarrow & \text { Collasuyu }\end{array}$

La distribución espacial de las comunidades, sus respectivas actividades productivas y el vínculo genealógico que existe entre ellas invitan a concebir un ordenamiento del territorio distrital alternativo al que se observa en la actualidad6. La extensión territorial de los ayllus parece haber sido mucho mayor ya que todos ellos orillan en el anexo Limaqpunku (lit. «puerta de Lima»), ubicado en la mitad septentrional ya entrada la ceja de selva. Yamamoto (1981) también identificó dos «sectores» o «aldeas» muy alejadas dedicadas exclusivamente a la actividad pastoril, Huaracone e Inca Cancha. En rigor, ambos sectores eran las únicas haciendas ganaderas de la región que, casi veinte años después a la reforma agraria, se reorganizan en comunidades7. Otro tanto ocurrió con Socapata, considerado como un sector o comarca «libre». Unión Araza, especializada en agricultura de piedemonte, fue un sector del ayllu que proclama su ascendencia. Los motivos así como los mecanismos mediante los cuales fue ejecutada esta reconfiguración territorial todavía son poco claros. Sin embargo, atendiendo a la antigua existencia y posible extensión de los cuatro ayllus hacia las tierras bajas —o viceversa-, el carácter satelital de tres de las comunidades de creación reciente y la evidencia etnográfica que se presenta a continuación, es posible imaginar que la orientación espacial de los ayllus haya sido la siguiente:

1. Collana Marcapata (noroeste)

3. Puiqa (suroeste)
2. Sahuancay (sureste)

4. Collasuyu (noreste)

Los fundamentos parentales de los ayllus marcapateños son similares al de los phinayenses8. Sin embargo, y al igual que en este último caso, el ayllu no se reduce a los vínculos de consanguinidad y afinidad que pueden inferirse de las genealogías. Los principios sobre los que descansa se expresan en un sinnúmero de contextos de interacción social tales como las formas de organización política, el acceso y usufructo del territorio, los trabajos colectivos, etc., que involucran una alta especialización ritual así como también un peculiar registro simbólico del tiempo y del espacio.

La posición central del pueblo (llaqta uhu) de Marcapata en el distrito es acentuada por la iglesia que se erige sobre él. Desplazado hacia el rincón sudeste del poblado, el edificio de factura colonial resulta un testigo fiel del proceso de evangelización tardía que durante el siglo XVIII sufrieron aquellas poblaciones ubicadas en sitios periféricos al Cusco, y que resultaban estratégicos en términos de sus potencialidades productivas. El valle, famoso por sus ricos cocales y su riqueza aurífera, presentaba una ubicación significativa como

6 La siguiente descripción corrige una primera caracterización de Marcapata y sus ayllus (Sendón, 2004) a partir de la información del trabajo de campo intensivo realizado en 2005 y 2007.

7 Por su especialización productiva y el lugar marginal que ocupan en el territorio distrital, ambas comunidades son a Marcapata lo que Phinaya a Pitumarca, presentando afinidades no solo entre sí sino también con las poblaciones pastoriles vecinas del departamento de Puno.

8 Esta generalización es producto de la encuesta genealógica realizada en los sectores Lacco y Chumpi del ayllu Collana Marcapata. Los resultados se publicarán oportunamente. 
antesala del Antisuyu, lo que atraía los intereses de misioneros franciscanos en su empresa evangelizadora de aquellas poblaciones que, desde la perspectiva de la capital imperial, se situaban más allá de los límites de la humanidad —algunos de los frescos que todavía visten las paredes exteriores del templo registran franciscanos adoctrinando a indios selváticos o ch 'unchus (Flores Ochoa et al., 1993)—. El patrón arquitectónico de la iglesia, similar al de una casa campesina, consiste en una nave rectangular de dimensiones considerables con techo de paja a dos aguas y está cercado por cuatro muros que, delimitando un corredor, lo aíslan del exterior. La puerta del muro oeste coincide con la entrada principal del templo y la del muro norte con la secundaria. En el vértice del ángulo que conforman estos dos muros se ubica el campanario, también con techo de paja. Cada cuatro años, el segundo lunes de agosto, el ritmo de la vida social marcapateña se ve alterado en virtud de la realización de un evento en el que participa la gran mayoría de la población: el cambio del techo de la iglesia o wasi chakuy (lit. «hacer la casa»). Esta actividad se prolonga a lo largo de toda una semana de acuerdo con el ritmo impuesto por una división ritual del trabajo que, a su vez, está estrechamente asociada con concepciones míticas acerca del origen mismo de Marcapata.

El primer día de actividades sienta las bases de la coreografía que se desplegará durante el resto de la semana. Ellas, comunes a todos los grupos, son siempre precedidas por Collana Marcapata. Los hombres de las ocho comunidades se acercan temprano en la mañana hacia los alrededores del templo cantando y bailando en un clima de exaltación ejecutando una coreografía que consiste en el arreo de una mula representada por una talla de madera. Junto con la mula, un grupo de muchachos (maq'ta waynakuna) que representan llamas, llevan en sus espaldas cargas de paja (ichhu q'epe) y mástiles de madera. Los miembros de Collana se ubican en la esquina de la iglesia correspondiente al campanario — al noroeste- clavan sobre su pared la talla de madera que representa a la mula y la cubren con una bufanda, a manera de tapado (wanku), para evitar que se espante y huya. El patrón de Collana, reconocido como «dueño de la mula» y encargado de regular las actividades que desarrollará su grupo, preside una mesa ritual en las afueras del templo. Las otras comunidades, precedidas por sus respectivos patrones, hacen lo propio ubicándose en el resto de las esquinas del templo. Es este el momento en el que se produce una verdadera metamorfosis: fusión de las comunidades hijas con sus respectivas madres, en virtud de la cual el espacio social es sometido a una división cuatripartita regida por el protagonismo que adquieren los cuatro ayllus. En efecto, tras congregarse en las esquinas del templo, los hombres de los cuatro grupos ingresan en los pasillos que lo rodean y cada uno de ellos erige una mesa, precedida por los respectivos patrones, al lado de las cuales se erigen cuatro postes de madera. Algunos de los miembros de cada grupo suben al techo de la iglesia y plantan en la cumbrera otros cuatro postes en línea recta a aquellos que se han erigido en la parte baja. Los postes en el techo delimitan la porción de la galera que le tocará techar a cada grupo. Así, el techo de la iglesia queda dividido en cuatro porciones, cada una patrimonio de un ayllu. La orientación espacial de estos últimos en las afueras del templo, en las mesas ubicadas en cada una de las esquinas de los pasillos que lo rodean y en el techo mismo es la siguiente:

1. Collana Marcapata (noroeste)

2. Sahuancay (sureste)

3. Puiqa (suroeste)

4. Collasuyu (noreste)

Esta distribución en el recinto sagrado se adecúa a la orientación espacial de los ayllus en el territorio distrital evocadas líneas arriba9 ${ }^{9}$. Cada una de las partes del techo está, a su vez,

9 En rigor, la mitad del mojinete del extremo noreste del edificio, denominada «Inca Yana», fue cedida hace unos años por el ayllu Collana a Yanacocha-Inca Cancha, quien también tiene una mesa con sus respectivos postes y mulas en la esquina correspondiente. 
subdividida en «surcos» (wachu) que parten de la cumbrera en dirección a cada agua. El hecho de que cada surco esté compuesto por decenas de cargas de ichhu y que el objetivo del techado sea cambiar las cargas viejas por nuevas, convierte al techo en un verdadero campo de cultivo. Pero, ¿de qué manera se lleva a cabo? Mediante el arreo de la mula.

Entre los postes que cada ayllu ha erigido en la cumbrera del templo y al lado de la mesa que ocupa en el pasillo se tiende un lazo sobre el que cuelga la mula, siendo el movimiento del lazo el que permite su desplazamiento. De la talla de madera cuelga un cencerro y de su base penden dos pequeños palos de madera que, en forma de «L», representan sus patas sobre las que se ata la carga de paja que deberá transportar la mula en sus múltiples viajes. Todo el trabajo está organizado alrededor de la mula y es precedido por sus respectivos dueños. Mientras que en la parte baja los miembros de cada grupo se encargan — jerárquica y respectivamente- de recibir a la mula, taparle su cabeza con una bufanda (wanku), preparar la carga de ichhu, cargar la paja en sus pies, destapar su cabeza y jalar el lazo que permitirá su ascenso al techo del templo, los miembros ubicados en las alturas realizan las tareas simétricamente inversas además, claro está, del cambio de ichhu. El primero de los viajes que realiza la mula, perteneciente a Collana Marcapata, está dedicado al descenso de la cruz que adorna la cumbrera de la iglesia. Una vez que la mula asciende a las alturas del techo, los miembros de Collana atan la cruz a su espalda y es recibida, esta vez, por los mayordomos de los cuatro ayllus ubicados en la entrada oeste del templo. Una vez recibida, los mayordomos trasladan la mula con la cruz al interior de la iglesia ubicándola en el altar. Tras haber descansado de su primera travesía, los mayordomos se dirigen a la plaza principal y, en procesión, arrean a la mula con su cruz la cual es guardada hasta que finaliza el ritual. A su regreso, los mayordomos devuelven la mula a Collana mientras que el ecónomo del templo cierra sus puertas, ya que durante el «repaje», el ingreso al interior de la iglesia está absolutamente vedado ${ }^{10}$. Los cuatro mayordomos ubican un nivel jerárquico superior a los patrones, y su función durante el ritual consiste en inspeccionar, visitar, saludar y estimular a cada ayllu en el cumplimiento de sus obligaciones. Ellos representan a los santos patrones de cada ayllu:

\section{Collana Marcapata: San Francisco de Asís}

\section{Puiqa: Virgen Purificada}

\section{Sahuancay: Collana Capaq}

4. Collasuyu: Virgen Concebida

La condición sexual de cada santo, dos masculinos y dos femeninos, es trasmitida a sus respectivos mayordomos quienes, durante el ritual, se dirigen entre sí —en tono de burla- como si efectivamente fuesen esposos y esposas. A su vez, cada ayllu tiene su propio apu —o divinidad tutelar cristalizada en la forma de una montaña - ubicado en las inmediaciones del pueblo. Sus nombres, de acuerdo con el orden jerárquico de los ayllus, son: Pachatusan, Piñuta, Sacsayhuaman y Huahuallani. El apu Pachatusan (lit., «sostén de la tierra») está ubicado al oeste al pueblo, enfrentando la entrada principal de la iglesia. Existe una íntima relación entre el santo del ayllu Collana, su propio apu y el héroe fundador de la iglesia marcapateña, Phuyutarki o, según la traducción vernácula, «aquél que viaja en la nube» $\mathrm{o}$ «aquél que monta la nube».

La iglesia de Marcapata tiene una historia que, a su vez, se inscribe en otra relativa a la misma fundación del pueblo y sus cuatro ayllus. Preguntado acerca de ella, un informante se pronunció al respecto especificando que, en un «tiempo anterior» y desde Asia, llegaron a la región tres «padres», cada uno de los cuales se dirigió a los pueblos de Pitumarca,

10 A diferencia de lo ocurrido en 2003, durante la última celebración del ritual, se omitió el ingreso de la mula en el interior del templo. 
Ollachea (provincia de Carabaya, Puno) y Marcapata. Marcapata fue el destino de San Francisco de Asís11:

«[...] Padre San Francisco acá venía, otro se ha ido a Ollachea, otro se ha ido a Pitumarca. Entonces acá han llegado, se han puesto un milagro éstos. Después se ha ido a Pachatusan, tres veces se ha ido a Pachatusan, así descalzo no más [...] A pedir, a pedir del Dios todopoderoso. Acostumbraban ir hacia el Pachatusan para pedir de Dios. Está un milagro el padre. Pero acostumbraban ir hacia el Dios todopoderoso. Para que los hombres puedan caminar así, él les enseñó. Y regresando de allí era en Marcapata. Y desde Marcapata los hombres lo observaron diciendo 'Le agarraremos'. 'No pues, en la pampa de Aqorumi será el pueblo. En allí vive'. Urgente lo han agarrado y lo han traído. Entonces, para que puedan hacer el pueblo empujaron las piedras desde aquel pueblo lejano. En allí están las piedras. Y así no querían vivir. Junto con eso hay un capulincito, en esa pampa Aqorumi, allí donde hay ese manantial de agua. Tenían que haber hecho un pueblito. No había querido vivir. Se iba. Y nuevamente aparecía, y nuevamente aparecía, él mismo en Marcapata. Entonces, por esa razón, es que lo observan diciendo 'Le vamos a agarrar'. Estos hombres de Marcapata desde el Pachatusan lo estaban observando una y otra vez. Y los hombres de Sahuancay desde Tinta, desde eso que lo llaman Amaru, desde allí. Y los hombres de Collasuyu desde Huahuallani. Y los hombres de Puiqa desde Sacsayhuaman. Entonces un día lo observan una y otra vez. ¿¿Dónde estará, pues? A ver, le vamos a agarrar. ¿Quién de nosotros le vamos a encontrar primero en allí?', diciendo. Y entonces, los que eran de Pachatusan le habían visto primero. Entonces había saltado, entró primero. Por eso es llamado Collana, por ese modo. Es Ilamado Collana ayllu, es definitivamente Collana. Y seguidamente, después, había llegado Sahuancay. Después Puiqa. Entonces esos le habían visto. Pero el que agarró a Pachatusan es Marcapata Collana. Por eso a ningún ayllu va su retrato, ni tampoco su imagen. Ese vive con cariño, con confianza, siempre en Collana. Algunos ayllus hacen un cargo. Por eso hay su monumento, su lámina. Eso también a ningún sitio tienen que soltar [...] Entonces, después, había visto Puiqa, había visto Sahuancay, Collasuyu no había visto, solo había escuchado. Así es, así es, diciendo no más ya, solo cuando ellos le habían avisado, después había llegado el chanakucha. Y por eso lo denominan chanaku [último hijo] ayllu. Entonces el primero es Collana, y después Sahuancay, luego Puiqa y después Collasuyu. De esa forma es el chanaku. Así de esa forma se formaron todos. Entonces, agarrando a ese, en el mismo lugar en Marcapata se quedó. En allá encima también está lo que han hecho, una capillita del papá Dios'12. Dicen que en esta pampa han hecho. Entonces, cuando no han querido, se lo han hecho en allí. Diciendo, 'Que el pueblo sea aquí', ordenó. Y así ya también Phuyutarki. Había sido madre soltera con hijo, allá en Sacsayhuaman. Entonces se había encontrado una warak'a [honda], y a su cintura se había amarrado. Por eso había aparecido embarazada. Entonces había dado a luz sin padre. Desde eso había sido Phuyutarki. Había dormido en la nube. Entonces, durmiendo en la nube, cuando apareció embarazada, eso con el cura habían hecho bautizar. Y así se lo había dado al cura para siempre. Entonces, aquí

11 Traducción literal de parte de una entrevista realizada en quechua al Sr. Cesario Condemaita Monroe (ayllu Collana) en julio de 2005. Agradecemos a la Sra. Georgina Maldonado por su ayuda en la traducción y transcripción de este y otros relatos que se presentan a continuación.

12 En las alturas del cerro Pachatusan se encuentra un pequeño techo a dos aguas de construcción reciente que alberga tres cruces. Más arriba aún, en la misma cima, se haya una cuarta cruz considerada como la más antigua. Estas cruces adquieren un protagonismo notable en ocasión de la celebración del Cruz Velakuy (3 de mayo). 
ya también el cura había caminado. Y así caminando se encontró con el Diablo, con el Diablo. Dice que a los hombres, pues, esto les dijo, '¿Dónde vas? ¿Qué quieren? Conmigo vamos a trabajar', diciendo, había dicho a Phuyutarki. Entonces había avisado al cura. Esto dice, 'Perdónale, no más. Di bueno', diciendo, le había

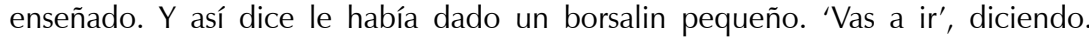
Entonces, 'En tu corazón está este kusi kusi [araña pequeña presagio de buena suerte]. Le vas a poner como chalina», diciendo, le había dicho. Entonces, en aquel manantialcito, en su huequito, en aquel pukara, dentro de allí, manantial manantialcito, ahí también había ido, en ahí había estado. Entonces, en ahí había estado. En allí le había puesto la chalina. Y entonces, en allí se había transformado en una mula. Para siempre no lo sueltan. Dice que era de no quitarle. Esa mulita era de no quitarle. Entonces a esa mulita se lo lleva para siempre. Ya está. Entonces, en allí, trabaja. En allí va a trabajar la mina de Choquekancha, de Kinsach'ata. Entonces, trayendo a la mula con ese fundaron el pueblo en Marcapata. Dice que Phuyutarki, Mamani, dice que ellos en ese tiempo habían sido hombres. Dice que en compañía de ellos trabajan. Phuyutarki en compañía de la gente. Después él dice a Lima va, por Limaqpunku. Para regresar no más, a comer un poquito. Entonces así yendo a Lima está. Entonces, ya cuando estaba, dice ya muchas veces, así está yendo ida y vuelta. Entonces, dice, él no más está fundando a Olleachea. Dice que siempre él está fundando en Olleachea también, también en Pitumarca, también aquí en Marcapata. En los tres siempre él es el principal fundador [...] En allí a su animalito había dejado a una abuelita. Entonces cuando no apareció, la abuelita había dicho 'Este animal creo que está de sed', diciendo. Le había soltado ese su bozal, su rienda. Su freno lo había sacado. Entonces, piuuuuu, diciendo, corriendo se había ido. Después él, parece que después de un mes completo, había llegado a Marcapata. En mucho tiempo. Había llegado en más de un mes. Por esa causa así es. Qori tika [oro conservado en un plato], lleno de una vasija todavía se había quedado en aquel pueblo en el que trabajó, en Choquekancha. Y en Kinsachata el oro que había trabajado había dejado en una batea, en aquel río de Lirpuni. Entonces esas cosas eran así. Él hizo esas cosas a causa de que su mula escapó. Después fundaron ese pueblo del Cusco. Entonces estrenaron al padre. Entonces los cuatro mayordomos también salieron, salieron hacia los cuatro ayllus. En allí los mayordomos también hicieron, todos los hombres. Después al padre a Olleachea se lo había llevado. A media misa había venido el Diablo. Entonces 'De lo que te has ensillado en esa mula, ahora te lo voy a llevar', diciendo. Entonces en eso se termina eso. En eso se termina el padre Marcapata. [...]».

En otras dos versiones del mito (Sendón, 2004) las peripecias del héroe son relatadas con mayor precisión. Allí se cuenta que Phuyutarki era un sacerdote con poderes sobrenaturales debido a un pacto establecido con el Diablo —o mediante la dominación que ejerció sobre él al ponerle una brida-. El Diablo se transformó en la mula que le permitía transitar velozmente largas distancias por debajo de la tierra. Al héroe se le atribuye la construcción de las iglesias de Marcapata, Pitumarca y Ollachea —-separadas entre sí por una geografía difícil pero que vuelve a delinear los contornos del espacio articulado por los antepasados de los phinayenses-. Phuyutarki detentaba una fuerza sobrehumana que le permitía mover piedras de gran tamaño para la construcción de las iglesias que no se encuentran en los sitios en los que han sido edificadas. A su vez, disponía de grandísimas cantidades de oro que favorecían la realización de su empresa — se cree que debajo de las cuatro esquinas de la iglesia de Marcapata se conservan cuatro gigantescos p'uyñus llenos de oro, el tesoro escondido de Phuyutarki-. El héroe tenía la costumbre de asistir a misa 
en Lima viajando con su mula desde el anexo Limaqpunku. En uno de estos viajes, antes de ingresar a la iglesia se encontró con una anciana a la que le pidió que vigilase su mula rogándole expresamente que bajo ninguna circunstancia le quitase la brida. La mula —o el Diablo hastiado de serlo— masticó la brida y sangró por su boca provocando así piedad en la anciana quien, al final, se la quitó. El Diablo, liberado del sortilegio, escapó velozmente impidiendo a Phuyutarki regresar a Marcapata y, perdiéndose en el camino, dejó inconclusa su obra —la finalización de las tres iglesias13-.

El wasi chakuy marcapateño sienta el escenario en el que cada cuatro años se dramatizan los trabajos y los días de Phuyutarki. Así como las comunidades se repliegan en los ayllus a largo del ritual, la iglesia, cerrada durante la semana de actividades, pareciera también replegarse ante el protagonismo que adquiere su techo y los dos únicos personajes que lo transitan: Phuyutarki y su mula. Asimismo, la grandísima cantidad de ichhu acumulado que cubre literalmente el edificio y sus alrededores anula virtualmente su eficacia simbólica remitiendo a un «tiempo anterior» al de su presencia en el pueblo e, inclusive, a la de Phuyutarki mismo.

\section{LOS AYLLUS DEL ORIENTE DEL CUSCO EN PERSPECTIVA COMPARATIVA CON EL COLLASUYU}

Aunque desde la perspectiva general que ofrecen los estudios de parentesco en los Andes del centro-sur peruano, algunas de las características sobresalientes del caso Phinaya (generalizables también a Marcapata) pudieran resultar atípicas, ellas se adecuan a la casuística proveniente del Collasuyu. La primera es el protagonismo de la agnación en un sistema en el que, tanto en el plano terminológico como en el de la acción, la bilateralidad constituye una de sus características definitorias (Lambert, 1977). Sin embargo, la agnación es una característica constitutiva de toda población pastoril, y la mayor concentración de poblaciones dedicadas al pastoreo en el sur peruano está ubicada sobre un eje espacial - cuyo vértice pareciera ser el nevado Ausangate-que se extiende en dirección sudeste, hacia el Collasuyu. Olivia Harris, en relación al ayllu Laymi (que combina agricultura y pastoreo) del norte de Potosí, se pronuncia de modo elocuente al respecto:

«Mientras que la linealidad no es enfatizada entre los laymis, la 'bilateralidad' de sus reglas de parentesco se ve en realidad sesgada hacia formas de descendencia y prácticas de residencia masculinas. La tierra es controlada en grandes unidades por unas pocas personas que asignan parcelas a sus agnados. La mayoría de los laymis tiene acceso a la tierra a través de vínculos agnaticios y consecuentemente forma un grupo corporado agnaticio en ciertos contextos. Como resultado el matrimonio es usualmente virilocal, a menos que una mujer heredase [tierras] en ausencia de herederos masculinos. Por lo tanto, mientras que en términos formales las relaciones de parentesco están basadas en principios cognáticos, en la práctica los principios agnáticos son de mayor importancia en el nivel local. En cualquier caserío es muy probable que exista un núcleo de hombres relacionados agnáticamente cuyas mujeres, foráneas, estén relacionadas entre sí principalmente a través de la mediación de sus maridos» (Harris, 2000: 170; traducción del autor).

Una segunda característica del ayllu phinayense compete al carácter estructuralmente relativo de los qatay y qhachun. Los análisis de parentesco que se han concentrado en

13 La única de las tres iglesias que en la actualidad todavía conserva su techo de paja es la de Marcapata. 
estos términos por lo general han subrayado el estatus de subordinación en el que se encuentran los individuos a quienes les son reservados, debido a su condición de «extraño» y «ajeno» para con aquellos que los emplean -inclusive, se ha insistido en que ello está relacionado con una dinámica de parentesco dominada por una lógica dador-receptor de esposas (Sendón, 2006)—. Sin pretender negar este valor —más bien negativo— de los términos, es fundamental no perder de vista su valor positivo ya que, en definitiva, siempre se es qatay (o qhachun) de alguien pero también para alguien. Olivia Harris, nuevamente, en una discusión acerca de la relación entre afinidad y alteridad en Andes y Amazonía, se refiere a esta condición relativa del estatus afín:

«Es valioso subrayar, sin embargo, que estas relaciones de exterioridad o alteridad son en principio recíprocas. Si un hombre trata al esposo de su hermana o de su hija como un predador de afuera, él simultáneamente cumple este rol con respecto a los parientes de su propia esposa. De manera similar, los nativos amazónicos quienes conciben a los extraños como potenciales caníbales así como también potenciales afines, son indudablemente conscientes que ellos son percibidos de manera similar por otros» (Harris, 2008: 292; traducción del autor).

Finalmente, es valioso advertir el rol destacado que ocupa uno de los dos términos homólogos al par qatay-qhachun en aymará -i.e., lari-tullqa, respectivamente- en lo que respecta no solo a las formas de organización social del Collasuyu en sus versiones precolombinas y coloniales tempranas, sino también por remitir a una noción (relativa) de ancestro. Aunque el término lari adquiere una relevancia notable en los análisis de la base parental de las elites cuzqueñas y del Collasuyu, el valor asociado en calidad de afín cambia según la perspectiva desde la que se lo considere. Efectivamente, en su búsqueda de un modelo andino prehispánico del ayllu cuzqueño real, similar al elaborado a partir del modelo genealógico descrito por Pérez Bocanegra, Tom Zuidema encontró en los datos del universo aymará un ejemplo adecuado:

«Este primer ejemplo proviene de la lengua aymará y se encuentra en el diccionario de Ludovico Bertonio (1612) con las siguientes glosas: Lari significa 'parientes masculinos de una mujer' y, agrega Bertonio, 'este término es también usado por ese hijo de mujer para designar aquellos mismos parientes masculinos de su madre'. La reduplicación de la palabra, lari lari, define su contexto territorial: se aplica a los alrededores de una ciudad o un pueblo donde viven los no parientes, los incivilizados, la gente sin ley. En el mismo contexto, Bertonio también proporciona el término quimsacallco lari para todos los parientes de la esposa. El significado literal del término es 'el octavo lari'. ¿Qué son entonces esas ocho categorías de lari? Creo que el término se comprende mejor como una designación para el grupo de ocho líneas posibles —una línea agnática y siete líneas cognáticas - que constituyen la descendencia de un hombre a lo largo de cuatro generaciones» (Zuidema, 1990: 25-26; traducción del autor) ${ }^{14}$.

En su discusión sobre las estirpes señoriales de la confederación Qaraqara-Charka entre los siglos XV-XVII (norte de Potosí), Tristan Platt, Thérèse Bouysse y Olivia Harris ponderan el sentido del término «casa» para describir la base parental de las elites locales advirtiendo el lugar que ocupaban los afines en un contexto patrilineal:

14 Zuidema también se pronuncia al respecto en relación a los rituales de cosecha de la zona del lago Titicaca: «[...] la versión duplicada de la palabra, lari lari, hace referencia a 'la gente de la puna, aquellos que no reconocen un cacique'. El sinónimo choquela agrega el detalle de que ellos subsisten de la caza, mientras que otro sinónimo, lari uru, los compara con los pescadores sucios e incivilizados Uru del lago Titicaca» (Zuidema, 1989: 266; traducción del autor). Lari, asimismo, significa «zorro», animal predador por excelencia en los Andes. 
«[...] En su acepción social, el término 'casa' se refiere al grupo familiar y a sus descendientes. Además se distinguen las 'casas mayores' de las 'casas segundas'; las primeras representan la línea del mayorazgo y las segundas las líneas de los hijos menores. Las distintas ramas, sean mayorazgo o casas segundas, que componen las casas se reconocen un antepasado común (en aymara, un 'Tata'). Bertonio traduce por 'cepa de la casa' los términos achachi, tunu achachi o apachi, que corresponden respectivamente al ancestro (achachi) o a la ancestra (apachi). El tunu era, en este caso, el tronco de la familia originaria, cuyas raíces eran constituidas tanto por un hombre como por una mujer. El ramo femenino era designado bajo el nombre de tunu lari, siendo lari todos los varones parientes de parte de la madre. Sin embargo, es el mayor o el más aptos de los tíos paternos (awki) quien, al parecer, tuvo que desempeñar el papel de sustituto del padre en la sucesión, cuando éste moría o se retiraba de su cargo por enfermedad [...] La pertenencia a dos casas y la importancia del ramo materno muestran en muchos casos, además, que las alianzas matrimoniales a veces pudieron pesar tanto o más que la descendencia 'en línea paterna'» (Platt et al., 2006: 663-664).

El ayllu en Phinaya designa a un universo social compuesto virtualmente por parientes consanguíneos y afines. Los segundos son clasificados a través de los términos de qatay y qhachun (al primero de los cuales la literatura le asignó un valor negativo, asociado con lo «exterior», lo «ajeno» y lo «subordinado»). Sin embargo, el valor que detenta es más bien relativo, y está vinculado con el proceso mismo de conformación y renovación del ayllu. Este aspecto - conjuntamente con la variable de orden morfológico relativa a la agnación - se ha subrayado en relación con la casuística del Collasuyu. Por otra parte, el término qatay es homólogo al aymará lari. De acuerdo con las fuentes tempranas el segundo, además de estar asociado con lo exterior, la puna, el agua, la caza y la pesca, la ausencia de gobierno y de ley, en su acepción tunu lari invoca una noción de ancestralidad (tunu) también relativa ya que, si bien subordinado con respecto a la línea paterna (achachi, tunu achachi, awki) en materia de sucesión, en términos de las alianzas matrimoniales su rol parece haber sido destacado15. Qatay, entonces, es un término que designa afinidad; lari, además de afinidad, involucra una noción de ancestralidad. ¿Es posible predicar lo mismo con respecto a qatay? De ser así, los ayllus del oriente del Cusco compartirían con sus pares del Collasuyu otra característica, en este caso, fundamental: el reconocimiento del afín no solo como parte del universo social sino también como eslabón constitutivo y generador de él. La respuesta a esta interrogante, sin embargo, no se reduce a la identificación formal de las permutaciones terminológicas entre los grupos involucrados. Todos ellos, en virtud de sus especializaciones productivas, prácticas rituales y creencias mitológicas, parecieran delinear los contornos de un espacio social que comparte, y por el que transitan, un conjunto común de ideas.

La versión presentada del mito de origen de Marcapata brinda una serie de información que invita a concebir la figura de Phuyutarki como la de un verdadero «Tunupa» (Bandelier, 1904; Bouysse-Cassagne, 1997) adecuado a las condiciones vernáculas y, en este sentido, responder a la pregunta formulada en el párrafo anterior. Aunque los roles de San Francisco y Phuyutarki están caracterizados separadamente, sus figuras parecieran por momentos

15 Desconocemos etnografías contemporáneas en las que el rol del lari se haya descrito en términos de este carácter relativo, siendo ello la razón fundamental por la que la información etnohistórica sobre el Collao resulta imprescindible para el desarrollo de la presente línea argumentativa. La misma condición queda demostrada en el rito de pasaje aymará o sucullo, celebrado en ocasión de la cosecha de papas, en el que los niños de pecho ingresaban al universo social una vez que sus tíos maternos, lari, les untaban sus rostros con sangre de vicuña (Bouysse-Cassagne, 1986 [1978]). 
confundirse. En un primer momento del mito se afirma que uno de los tres «padres» provenientes de Asia, San Francisco, se dirige a Marcapata pero, en un segundo momento, se afirma que fue Phuyutarki mismo quien fundó no solo Marcapata sino también Pitumarca y Ollachea. De igual modo, el destino final de la mula ubica a ambos personajes en un plano también ambiguo. Si bien la mula desaparece cuando la anciana, en Lima, le quita su freno, al final del relato vuelve a aparecer en Ollachea, donde San Francisco había Ilevado a Phuyutarki desde Marcapata. Si bien San Francisco le quita la mula a Phuyutarki, ejercitando sobre él una verdadera conversión, lo cierto es que la suerte final de ambos se funde en un mismo personaje: «el padre Marcapata». Es decir, en tanto dueño de la mula Phuyutarki — hechicero que se desplaza por debajo de la tierra - recuerda a aquel indio natural de Carabuco llamado Anti, del cual cuenta Guaman Poma de Ayala (1987 [1615]) que también fue un hechicero que vivía en una cueva habitada por el mismo demonio y fue convertido por San Bartolomé. Ahora bien, en tanto «padre» que convierte al diablo en mula, sometiéndolo a sus propios designios, Phuyutarki mismo es Tunupa y, en calidad de «tunu», antepasado y ancestro fundador ${ }^{16}$. Se trata, sin embargo, de un antepasado «de un tiempo anterior» asociado con lo exterior, lo salvaje, la ausencia de gobierno y lo húmedo (Phuyutarki, hijo de la nube, lleva también su nombre, phuyu); es decir, con todo aquello que visiblemente dificulta el trazado de una genealogía de contornos precisos.

Si Phuyutarki-Tunupa remite a una tradición mitológica del Collasuyu, el tiempo anterior a él mismo podría también estar vinculado con ella. Y, en efecto, resulta sorprendente escuchar en la actualidad de los labios de los marcapateños el mismo mito de las ch 'ullpas que, entre tantas otras versiones, fuera relevado por Alfred Métraux (1935) y Nathan Wachtel (2001 [1990]) entre los chipayas de Carangas en Bolivia17:

«Las ch 'ullpas antes eran hombres. En el tiempo de la luna, solamente luna había. En ese tiempo trabajaban la papa, también el maíz, también las lisas, oca, añu, todo. Siempre habían sus vacas, también sus caballos, sus llamas. No había alpaca. Solo eso había. Solamente la noche trabajaban. Sus papas daban frutos solamente tres. Una para semilla, una para $c h^{\prime}$ 'uñu, también uno para papa. Las ch 'ullpas decían... Antes no había sol. Solo en la noche, solo en la luna estaban. Y entonces ellos fueron a la cueva a ocultarse. Al sol ellos le decían, 'Awqaysunkha va a salir de allá hacia acá', diciendo. Ellos a las cuevas se fueron a esconder. De este lado iba a salir el sol. Y entonces fueron a esconderse a ese lado. Entonces el sol salió desde el lado en que se habían escondido. Desde entonces ellos se han secado en las cuevas. Se han secado. Y algunos por el agua se entraron hacia el monte; a la selva. Y entonces algunos en allí todavía están vivos hasta ahora. Ahora están ch 'unchus, están ch 'unchus. [...] No se encuentra con la gente. Dice que esos saben mirar la coca, matar a la gente. Ahora en aquí están todavía las ch 'ullpas secadas. Todavía continúan sus huesos, sus cabezas también. En Chumpi ahora están todos. Ahora están muertos no más ya, huesos no más ya. Secados por el sol».

En esta versión del mito se hace referencia a los puntos cardinales sin especificación alguna, ya que el informante los estaba señalando con su brazo. Las ch 'ullpas eran los

16 La terminología de parentesco quechua empleada en Marcapata para designar a los antepasados de la segunda generación ascendente cuenta con la raíz tunu. Mientras que los términos de referencia para designar a los abuelos y abuelas (paternos y maternos) lineales son, respectiva y exclusivamente, machulay o hatun taytay y awichay o hatun mamay, sus respectivos hermanos y hermanas - i.e., los abuelos y abuelas colaterales- pueden ser referidos, alternativa y respectivamente, como tunuchay o tunu machulay y tunu awichay.

17 Traducción literal de la versión narrada por el señor Luis Francisco Huaracayo Bedoya (ayllu Collana) en Marcapata en julio de 2005. 
seres del tiempo presolar que construían sus casas con las puertas en dirección hacia el oeste. Al enterarse de que el sol iba a aparecer desde esa dirección, decidieron dar vuelta a la orientación de las puertas hacia la dirección contraria. El sol apareció por el Este y las incineró, dejando como único testimonio de su existencia las casas quemadas con sus puertas en dirección al levante18. Por otro lado, las ch 'ullpas denominaban al sol «awkaysunkha», término que en quechua, literalmente, significa «mi enemigo barbudo». Una primera definición del término asocia de manera metonímica las barbas del enemigo con los rayos solares. Finalmente, no todas las ch'ullpas perecieron. Algunas de ellas pudieron escapar por los ríos en dirección al piedemonte, y en la selva del Antisuyu se convirtieron en los bárbaros ch 'unchus que pueblan la región. Es notable, entonces, la manera en que este mito se relaciona con tres hechos significativos relativos al wasi chakuy y a su héroe fundador. En primer lugar, la dirección de la entrada principal de la iglesia, hacia el oeste enfrentando al apu Pachatusan, reproduce la dirección de las puertas de las casas de las $c h^{\prime}$ ullpas ${ }^{19}$. En segundo lugar, la salida del sol, enemigo barbudo, coincide con la fundación de la iglesia por parte de Phuyutarki quien, como Tunupa, es asimilado a la figura de un hombre blanco que llevaba barbas en su rostro. Sin embargo, y en tercer lugar, el hecho de que el destino final de las ch 'ullpas sobrevivientes sea la región selvática del Antisuyu se adecúa bastante bien a lo ocurrido en la región lacustre del Collasuyu —en ambos casos húmedas o acuáticas- e, inclusive, al carácter también acuático de Phuyutarki quien, así, se presenta como el homólogo complementario del indio hechicero anti de Carabuco.

Los mitos de Phuyutarki y las ch 'ullpas en el contexto marcapateño proponen una primera ecuación en la que se conjugan nociones tales como «lo exterior», «lo foráneo», «lo salvaje», «lo acuático», «lo incivilizado», etc.; las mismas que han sido predicadas respecto al término lari y su homólogo qatay. Sin embargo, en el análisis de estos últimos términos hemos concebido la posibilidad de advertir un valor relativo cuya dimensión «positiva» todavía resta definir. Para ello es preciso establecer si los discursos míticos o las prácticas rituales proponen, efectivamente, algún tipo de relación entre, por un lado, las ch 'ullpas y los qatay o lari y, por el otro, las ch 'ullpas, los qatay o lari y alguna noción de ancestralidad tal como la que encierra el término tunu.

En su etnografía sobre los pastores del ayllu K'ulta del departamento de Oruro (Bolivia), Thomas Abercrombie relevó una versión del mito de las ch 'ullpas en el que la figura del sol está corporizada en un personaje denominado Tatala — hombre foráneo, viejo y barbudo también conocido como Jesucristo- quien fue el responsable de su destrucción. Algunas de las ch 'ullpas pudieron escapar del cataclismo sumergiéndose en los lagos de la región y, refugiándose en las zonas más apartadas y elevadas, se convirtieron en cazadores y pescadores que vivían sin ley y sin reconocer jerarquía alguna. Esta batalla primigenia, generadora de la humanidad, se expresa en todo el universo ritual k'ulta. El sacrificio de las llamas, por ejemplo, pone en juego una serie de categorías sociales entre las que sobresalen, además del propio auspiciante, sus parientes consanguíneos, sus afines y el propio Tatala, en un escenario ritual que garantiza a los k'ulta el acceso al poder de la eucaristía:

«El 〈sacrificio〉 de los tomadores de esposas (como jañachus) y los hombres jóvenes de la patrilínea misma del auspiciante masculino (como un tipo no específico de

18 En las otras versiones del mito (hemos recopilado nueve — seis de ellas en quechua - sobre las que estamos trabajando para su próxima publicación) estas especificaciones se hacen explícitas. A su vez, las casas de las ch'ullpas son en realidad cuevas (machay) diseminadas por todo el territorio distrital.

19 El hecho mismo de que el edificio se mantenga cerrado durante la semana de trabajo invita a concebirlo como una gigantesca ch'ullpa. 
llama) los caracteriza como miembros del rebaño del cual el auspiciante es al mismo tiempo el líder macho (llantiru) y el pastor (awatiri). De este modo el auspiciante adopta los roles de la víctima ideal del sacrificio en el rebaño humano, el llantiru, y la del sacrificador de ese rebaño, el awatiri, y especialmente la de Tata Awatir Awksa, «Nuestro Padre Pastor», es decir el Cristo-Solar o Tatala. Su rol dual es consistente tanto con la función social de autoridad, que debe mediar entre el grupo y la autoridad estatal por ser simultáneamente miembro de ambos órdenes, así como con una visión internalizada de la naturaleza de las relaciones hegemónicas entre, por un lado, el Estado y su asociación con los dioses celestiales y, por el otro, la sociedad k'ulta y sus dioses locales, pastores de animales del mundo de abajo» (Abercrombie, 1998: 399; traducción del autor).

Abercrombie especifica que jañachu (lit., «estéril») es un término que también se aplica a la alpaca semental, considerada más débil y difícil de criar que el llantiru —la llama macho objeto del sacrificio-y, en este sentido, difiere categóricamente de él. Además, la relación entre Ilantiru y jañachu se asemeja a la que existe entre el auspiciante del ritual (fuerte, fértil y líder masculino) con sus tullqas (o «tomadores de esposas» que, en el ritual, asumen un rol subordinado). Si el vínculo llantiru-jañachu corresponde al vínculo auspiciante-tullqa, el primero debería ser lari para el segundo, ya que el auspiciante es el arquetipo del «grupo dador de esposas»20. De igual manera, si en calidad de sujeto del sacrificio el auspiciante se identifica con el par awatiri-Tatala, en calidad de objeto de sacrificio su identificación con el llantiru remite necesariamente a la noción de ch 'ullpas, los seres del tiempo presolar sacrificados por el mismo Tatala. Proponemos, a partir de este ejemplo, la hipótesis de que el par llantiru-jañachu se corresponde con las parejas lari-tullqa y ch'ullpas-Tatala permitiendo, así, determinar una instancia de identificación de las ch 'ullpas con los laris o los qatay.

El vínculo lari (y eventualmente qatay)-ch 'ullpas todavía remite a esa esfera (negativa) de la vida social asociada con lo prehumano, lo salvaje, lo incivilizado y la muerte. ¿Existe, entonces, alguna relación entre el universo simbólico contenido en estos términos y la vida social propiamente dicha? Es decir, ¿existe alguna instancia en la que la relación entre la prehumanidad de las ch 'ullpas y la sociedad humana no sea concebida en términos antagónicos? Una segunda versión del mito de las ch 'ullpas recopilada en Marcapata es explícita al respecto21:

«Ch'ullpa antiguo inca. Eso es inca Pacha Kuraka. Ellos son incas, ellos son los llamados Pacha Kuraka inca, son llamados. Por eso ellos son awki. «Hacia ellos debemos ofrendar», diciendo. «Mi abuelo Pacha Kuraka, acuérdate de mi, para estos tus hijos, para estos tus nietos, oro, plata, herencia envíame tú a mì. Él acostumbra comer con contribución, con patente. Yo acostumbraba decirle todo, «Envíame, acuérdate de mis, diciendo, debemos decir al awki. Entonces esos son hombres del tiempo ch 'ullpa. Todavía no era tiempo de papá Dios. Cuando el hijo de Dios

\footnotetext{
20 Abercrombie (1998) traduce lari como «dador de esposa» y tullqa como «tomador de esposa». La discusión en torno a qatay o qhachun como grupos dadores y receptores de esposas estuvo centrada alrededor del término caca o «hermano de la madre» que, opuesto al primero, hace de él el grupo receptor y del segundo una subcategoría del grupo dador. Más allá de que la insistencia en la lógica dador-receptor de esposas trae aparejada una serie de problemas relativos a la interpretación de la casuística etnográfica (Sendón, 2006), lo cierto es que desde esta misma lógica la homología entre los términos quechua y aymará parece quedar contradicha: mientras que en aymará lari y tullqa remiten, respectivamente, a los grupos dadores y receptores, en quechua la situación se invierte. Pensamos, sin poder explayarnos aquí al respecto, que esta contradicción está ligada a una fuerte insistencia en la lógica dador-receptor que, en cierto modo, impide apreciar el carácter estructuralmente relativo de los términos —al menos en su versión quechua tal y como fueron generalmente interpretados (Sendón, 2006)—.

21 Traducción literal de otra parte de la entrevista realizada al señor Cesario Condemaita (cf. nota 14).
} 
no estaba allí esos hombres habían. Entonces ellos caminaron solo en esa luna, eran. Entonces solo en esos cerros altos hicieron sus casas. Porque las pampas eran limbu [limbo], no hicieron en debajo de la tierra. Entonces, cuando ellos se sequen, cuando todavía no haya sol, para que ellos puedan salirse. Diciendo «El sol nos va a secar, hacia las cuevas se entraron para siempre, a los manantiales para siempre. Algunos se entraron para siempre hacia la yunka. Esos machulas son hombres de ese tiempo. Entonces algunos enteros no más están en los pedregales, en las cuevas. [...] Eso es machula. Antes de Cristo todavía había pues esas gentes. Así pues dicen esos son los machulas, eso es ch 'ullpa».

La identificación de las ch 'ullpas como «abuelo Pacha Kuraka», «awki» o «machula», a quienes sus «nietos» deben ofrendar, demuestra que su protagonismo en el mundo de los humanos está expresado en términos de un vínculo de parentesco que remite, en última instancia, a una noción de ancestralidad que, por una suerte de transitividad, es trasmitida también al universo de los afines. En efecto, si existe un vínculo entre las ch 'ullpas y los laril qatay, y otro entre las ch 'ullpas y el tunu (antepasado), existe también una asociación entre los mismos lari/qatay y el tunu que, como término de parentesco específico - tunu lari-se sabe que hacía referencia a todos los parientes varones del ramo femenino del tronco de la familia originaria (Platt et al., 2006). Sin embargo, al igual que lo observado con respecto a los qatay (y qhachun) en Phinaya, esta condición de ancestro es estructuralmente relativa22. Las ch'ullpas, así como los qatay o lari, si bien ancestros, no dejan de pertenecer a ese universo de lo exterior, lo foráneo, lo salvaje, lo incivilizado y, por supuesto, lo prehumano. Sin embargo, el salto que existe entre ese universo y el universo social de lo humano no es insalvable.

\section{CONSIDERACIONES FINALES}

Hemos afirmado al inicio de este trabajo que el ayllu en los Andes es sinónimo de parentesco y organización social, con el fin de distinguirlo de otras formaciones sociales, precisar sus contornos, definir sus fundamentos y explicitar los mecanismos que posibilitan su constitución y reproducción a lo largo del tiempo. Ahora bien, también insistimos en que el ayllu no se reduce exclusivamente a ello. Su cabal comprensión amerita combinar una serie de perspectivas de análisis tales como la organización colectiva del trabajo, las prácticas rituales y las creencias mitológicas. Sin embargo, todos estos aspectos se expresan en el lenguaje del parentesco. En definitiva, el ayllu remite a una dimensión parental de la vida social que, al expresarse en el ritual y la mitología, la trasciende en el sentido de que las relaciones de parentesco involucradas no solo se restringen al universo social de los humanos vivos.

La casuística relativa a los ayllus ubicados en la porción oriental del departamento del Cusco no solo confirma esta caracterización general sino que, al hacerlo, se relaciona bastante bien con otra desvirtuando las divisiones político-administrativas impuestas por la sociedad mayor. En sus aspectos morfológicos así como en los temas desplegados en la mitología y el ritual, las formas de organización social de las poblaciones del oriente cusqueño

22 Con otro tipo de respuesta en mente, Abercrombie también ha subrayado este carácter relativo de la condición de ancestro: «¿Cómo una historia que no se refiere a los ancestros humanos propiamente dichos puede dar cuenta de los orígenes de quienes la relatan? Sugiero que la ambivalencia de los k'ulta acerca de sus orígenes y su falta de disposición a trazar su ascendencia a las Chullpas o a Tatala expresa la contradicción colonial inserta en el corazón de la historia; y la contradicción misma así como también el método de la historia para resolverla explica la ontología k’ulta» (Abercrombie, 1998: 326; traducción del autor). 
comparten características significativas con sus homólogas del Collasuyu, delineando un espacio social que quizás hasta no hace mucho tiempo pudo haber estado articulado a lo largo de una ruta del oro y de la coca, transitada por pastores y muleteros bajo el acecho de los indios ch 'unchus. Ello, a su vez, invita a concebir la posibilidad de que los vínculos entre poblaciones de tierras altas y tierras bajas de esta porción de los Andes centrales no estuvieran solo articulados a lo largo de un eje oeste-este — desde el Cusco hacia el levante- sino también a lo largo de otro, más fluido, sur-norte — es decir, desde el Collasuyu al Antisuyu, y viceversa-. Ello explicaría, entre otras cosas sin duda, la condición «ch 'ullparia» de los ch 'unchus del Anti, el carácter de «tunu» del héroe Phuyutarki y la posición estructuralmente relativa de unos y otros en sí mismos y en su íntima relación.

Por supuesto que este espacio (cuyo límite ha sido apenas sugerido en la fig. 1), las poblaciones que lo habitaban y lo transitaban y sus respectivas formas de organización social han sufrido serios trastornos. Estas transformaciones, sin embargo, no se produjeron sobre una masa humana carente de medios para canalizarlas y reelaborarlas bajo los fundamentos de una lógica que no tiene por qué ser la misma que aquella que las impulsó. Dichos fundamentos parecieran estar relacionados con aquellas variables que definen al ayllu las cuales, a su vez, se despliegan a lo largo de una escala temporal de difícil cuantificación. Con esto no se pretende insinuar que el ayllu, sus fundamentos parentales, las prácticas rituales que lo perpetúan y sus héroes fundadores no estén exentos, a su vez, de reelaboraciones - problema acerca del cual hemos deliberadamente guardado silencio en estas páginas-. En relación con la casuística etnográfica discutida, lo que se ha pretendido subrayar es que las características definitorias del ayllu de la porción oriental del departamento del Cusco presentan una serie de atributos propios de sus pares del Collasuyu, que estos atributos, en más de un sentido relacionados con las dinámicas propias de una sociedad de pastores, delimitan un espacio social en sí mismo y que, finalmente, la ideología (en el sentido «dumontiano» del término) imperante en su interior no solo plantea diferencias con respecto a las características definitorias de las formas de organización social de otras regiones de los Andes peruanos, sino que también en ella están presentes elementos de «larga duración».

\section{Referencias citadas}

ABERCROMBIE, T., 1998 - Pathways of memory and power: Ethnography and history among and Andean people, 603 pp.; Madison: The University of Wisconsin Press.

ALBER, E., 1999 - ¿Migración o movilidad en Huayopampa? Nuevos temas y tendencias en la discusión sobre la comunidad campesina en los Andes, 213 pp.; Lima: Instituto de Estudios Peruanos (IEP).

ARNOLD, D., 1998 - Introducción. De «Castas» a Kastas: Enfoques hacia el parentesco andino. In: Gente de carne y hueso. Las tramas de parentesco en los Andes (D. Arnold, ed.): 15-62; La Paz: Centre for Indigenous Amerindian Studies and Exchange (CIASE), Instituto de Lengua y Cultura Aymara (ILCA). 
BANDELIER, A. F., 1904 - The cross of Carabuco in Bolivia. American Anthropologist, 6 (5): 599-628.

BOUYSSE-CASSAGNE, T., 1997 - De Empédocles a Tunupa: Evangelización, hagiografía y mitos. In: Saberes y memorias en los Andes. In Memorian Thierry Saignes (T. BouysseCassagne, ed.): 157-212; París-Lima: Institut des Hautes Études de l’Amérique Latine (IHEAL), Institut Français d'Études Andines (IFEA).

BOUYSSE-CASSAGNE, T., 1986 [1978] - Urco and uma: Aymara concepts of space. In: Anthropological history of Andean polities (J. V. Murra, N. Wachtel \& J. Revel, eds.): 201-227; Londres-París: Cambridge University Press, Maison des Sciences de I'Homme.

DELER, J.-P., HURTADO, I., MESCLIER, É. \& PUERTA, M., 1997 - Atlas de la región del Cusco. Dinámicas del espacio en el Sur peruano, 206 pp.; Cusco: Centro de Estudios Regionales Andinos Bartolomé de las Casas (CBC), Instituto Francés de Estudios Andinos (IFEA), Instituto de Investigación para el Desarrollo (IRD).

FLORES OCHA, J., KUON ARCE, E. \& SAMANEZ ARGUMEDO, R., 1993 - Pintura mural en el sur andino, 359 pp.; Lima: Banco de Crédito del Perú.

GOLTE, J., 1992 - Los problemas con las comunidades. Debate Agrario. Análisis y Alternativas, 14: 17-22.

GUAMAN POMA DE AYALA, F., 1987 [1615] - Nueva crónica y buen gobierno (Tomo A), 373 pp.; Madrid: Historia 16.

HARRIS, O., 2000 - Complementarity and conflict: An Andean view of women and men. In: To make the Earth bear fruit: Ethnographic essays on fertility, work and gender in Highland Bolivia (O. Harris, ed.): 164-179; University of London: Institute of Latin American Studies (ILAS).

HARRIS, O., 2008 - Alterities: Kinship and gender in Latin American Anthropology. In: A Companion to Latin American Anthropology (D. Poole, ed.): 276-302; Oxford: Blackwell.

INAMURA, T., 1981 - Adaptación ambiental de los pastores altoandinos en el sur del Perú. Simbiosis económico-social con los agricultores. In: Estudios etnográficos del Perú meridional (S. Masuda, ed.): 65-83; Tokio: Universidad de Tokio.

LAMBERT, B., 1977 - Bilaterality in the Andes. In: Andean kinship and marriage (R. Bolton \& E. Mayer, eds.): 1-27; Washington: American Anthropological Association.

MÉTRAUX, A., 1935 - Les Indiens Uro-Čipaya de Carangas. Journal de la Société des Américanistes, XXVII (1): 111-128.

MOLINIÉ-FIORAVANTI, A., 1986 [1978]-The Andean community today. In: Anthropological History of Andean Polities (N. Wachtel, J. Revel \& J. V. Murra, eds.): 342-358; Cambridge: Cambridge University Press, Éditions de la Maison des Sciences de I'Homme.

MOSSBRUKER, H., 1990 - La economía campesina y el concepto de «Comunidad»: un enfoque crítico, 115 pp.; Lima: Instituto de Estudios Peruanos (IEP).

OSSIO ACUÑA, J. M., 1981 - Estructura social de las comunidades andinas. In: Historia del Perú, tomo III: 203-377; Barcelona: Editorial Juan Mejía Baca.

PLATT, T., BOUYSSE-CASSAGNE, T. \& HARRIS, O., 2006 - Qaraqara Charka. Mallku, Inka y Rey en la provincia de Charcas (siglos XV-XVII). Historia antropológica de una confederación aymara, 1088 pp.; La Paz: Instituto Francés de Estudios Andinos (IFEA), Plural Editores, University of St. Andrews, University of London, Inter American Foundation, Fundación Cultural del Banco Central de Bolivia. 
RICARD LANATA, X., 2005 - Introducción. In: Vigencia de lo andino en los albores del siglo XXI. Una mirada desde el Perú y Bolivia (X. Ricard Lanata, ed.): 9-21; Cuzco: Centro de Estudios Regionales Andinos Bartolomé de las Casas (CBC).

SATO, N., 1981 - El concepto de ayllu, y qata/q'ačun: Un estudio de la familia, el parentesco y el ayllu. In: Estudios etnográficos del Perú meridional (S. Masuda, ed.): 139-171; Tokio: Universidad de Tokio.

SENDÓN, P., 2001 - Phinaya: cambio y continuidad en una comunidad andina (Cusco). Scripta Ethnologica, XXII: 103-127.

SENDÓN, P., 2004 - El wasichakuy de Marcapata: ensayo de interpretación de una «Costumbre» andina. Revista Andina, 39: 51-73; Cuzco.

SENDÓN, P., 2005 - Migración y movilidad espacial en un pueblo de pastores de puna del sur andino. Actas del V Congreso Argentino de Americanistas: 201-223; Buenos Aires.

SENDÓN, P., 2006 - Los términos de parentesco quechua qatay y qhachun según los registros etnohistóricos y etnográficos: una interpretación. Revista Andina, 43: 9-58.

SENDÓN, P., en prensa - Estudios de parentesco y organización social en los Andes. In: No hay país más diverso II. Compendio de Antropología Peruana (C. I. Degregori, ed.); Lima: Instituto de Estudios Peruanos (IEP).

SKAR, H., 1997 [1982] - La gente del valle caliente. Dualidad y reforma agraria entre los runakuna (quechuahablantes) de la sierra peruana, 420 pp.; Lima: Fondo Editorial de la Pontificia Universidad Católica del Perú (PUCP).

YAMAMOTO, N., 1981 - Investigación preliminar sobre las actividades agro-pastoriles en el distrito de Marcapata, Departamento del Cuzco, Perú. In: Estudios etnográficos del Perú meridional (S. Masuda, ed.): 85-137; Tokio: Universidad de Tokio.

WACHTEL, N., 2001 [1990] - El regreso de los antepasados. Los indios urus de Bolivia, del siglo XX al XVI, 648 pp.; México: El Colegio de México, Fideicomiso Historia de las Américas, Fondo de Cultura Económica (FCE).

ZUIDEMA, R. T., 1989 - The moieties of Cuzco. In: The attraction of opposites: Thought and society in the dualistic mode (D. Maybury-Lewis \& U. Almagor, eds.): 255-275; Ann Arbor: The University of Michigan Press.

ZUIDEMA, R. T., 1990 - Inca civilization in CuzCo, 101 pp.; Austin: University of Texas Press. 